\title{
A SECOND-ORDER DIFFERENTIAL SYSTEM WITH HESSIAN-DRIVEN DAMPING; APPLICATION TO NON-ELASTIC SHOCK LAWS
}

\author{
Hedy Attouch, Paul-Emile Maingé and Patrick Redont
}

\begin{abstract}
We consider the second-order differential system with Hessian-driven damping $\ddot{u}+$ $\alpha \dot{u}+\beta \nabla^{2} \Phi(u) \dot{u}+\nabla \Phi(u)+\nabla \Psi(u)=0$, where $\mathscr{H}$ is a real Hilbert space, $\Phi, \Psi: \mathscr{H} \rightarrow \mathbb{R}$ are scalar potentials, and $\alpha, \beta$ are positive parameters. An interesting property of this system is that, after introduction of an auxiliary variable $y$, it can be equivalently written as a firstorder system involving only the time derivatives $\dot{u}, \dot{y}$ and the gradient operators $\nabla \Phi, \nabla \Psi$. This allows to extend our analysis to the case of a convex lower semicontinuous function $\Phi$ : $\mathscr{H} \rightarrow \mathbb{R} \cup\{+\infty\}$, and so to introduce constraints in our model. When $\Phi=\delta_{K}$ is the indicator function of a closed convex set $K \subseteq \mathscr{H}$, the subdifferential operator $\partial \Phi$ takes account of the contact forces, while $\nabla \Psi$ takes account of the driving forces. In this setting, by playing with the geometrical damping parameter $\beta$, we can describe nonelastic shock laws with restitution coefficient. Taking advantage of the infinite dimensional framework, we introduce a nonlinear hyperbolic PDE describing a damped oscillating system with obstacle. The first-order system is dissipative; each trajectory weakly converges to a minimizer of $\Phi+\Psi$, provided that $\Phi$ and $\Phi+\Psi$ are convex functions. Exponential stabilization is obtained under strong convexity assumptions.
\end{abstract}

Mathematics subject classification (2010): 34C35, 34D05, 65C25, 90C25, 90C30.

Keywords and phrases: asymptotic stabilization, convex variational analysis, dissipative dynamical systems, exponential stabilization, gradient-like systems, Hessian-driven damping, impact dynamics, nonelastic shocks, nonsmooth potentials, restitution coefficient, second-order nonlinear differential equations, unilateral mechanics, viscoelastic membrane.

\section{REFERENCES}

[1] P. Alart, O. Maisonneuve, R. T. Rockafellar, Nonsmooth Mechanics and Analysis, Advances in Mechanics and Mathematics, 12, Springer, 2006.

[2] F. Alvarez, J. M. PÉrez, A dynamical system associated with Newton's method for parametric approximations of convex minimization problems, Applied Mathematics and Optimization, 38, (1998), 193-217.

[3] F. AlvareZ, On the minimizing property of a second-order dissipative system in Hilbert space, SIAM J. Control Optim., 38, (2000), 1102-1119.

[4] F. Alvarez, H. Attouch, J. Bolte, P. Redont, A second-order gradient-like dissipative dynamical system with Hessian-driven damping. Application to optimization and mechanics, J. Math. Pures Appl., 81, (2002), 747-779.

[5] H. Aтtouch, Variational convergence for functions and operators, Pitman Advanced Publishing Program, Applicable Mathematics Series, 1984.

[6] H. Atтouch, Convergences de fonctionnelles convexes, Journées d'Analyse Non Linéaire, Besançon, Lecture Notes in Mathematics, Springer-Verlag 665 (1977), 1-40.

[7] H. Attouch, J. Bolte, P. Redont, Optimizing properties of an inertial dynamical system with geometric damping, Control and Cybernetics, 31 (2002), 643-657. 
[8] H. Attouch, G. Buttazzo, And G. Michaille, Variational Analysis in Sobolev and BV Spaces, MPS-SIAM Series on Optimization, 6, 2006.

[9] H. ATtOUCH, A. САвOT, P. REDONT, The dynamics of elastic shocks via epigraphical regularization of a differential inclusion, Adv. Math. Sci. Appl., 12, (1) (2002), 273-306.

[10] H. Attouch, X. Goudou, P. Redont, The heavy ball with friction method, Commun. Contemp. Math., 2, (1) (2000), 1-34.

[11] H. Attouch, P.E. Maingé, Asymptotic behavior of second order dissipative evolution equations combining potential with non-potential effects, ESAIM: Control, Optimisation and Calculus of Variations, Published online: 19 janvier 2011.

[12] H. ATtOuch, B. F. SVAiter, A continuous dynamical Newton-Like approach to solving monotone inclusions, SIAM J. Control Optim., 49, (2) (2011), 574-598.

[13] B. BAJI, A. САВОT, J. I. DiAZ, Asymptotics for some nonlinear damped wave equation: finite time convergence versus exponential decay results, Annales de l'Institut Henri Poincare (C) Non Linear Analysis, 24, 6 (2007), 1009-1028.

[14] P. Ballard, The dynamics of discrete mechanical systems with perfect unilateral constraints, Arch. Rational Mech. Anal., 154, (2000), 199-274.

[15] H. Brézis, Opérateurs maximaux monotones et semi-groupes de contractions dans les espaces de Hilbert, North-Holland, Mathematical Studies, 1973.

[16] H. BRÉZIS, Monotonicity methods in Hilbert spaces and some applications to nonlinear partial differential equations, in: Contributions to Nonlinear Functional Analysis, E. Zarantonello, ed., Academic Press, New York, 1971.

[17] H. BrÉZIS, Problèmes unilatéraux, J. Math. Pures et Appl., 51 (1972), 1-168.

[18] A. CAвот, L. PAOLI, Asymptotics for some vibro-impact problems with a linear dissipation term, J. Math. Pures Appl., 87 (2007), 291-323.

[19] S. Faik, H. Witteman, Modeling of impact dynamics: A literature survey, 2000 International ADAMS User Conference, 2000.

[20] J. K. HALE, Asymptotic behavior of dissipative systems, Math. surveys Monogr., 25, AMS, Providence, RI, 1987.

[21] A. HarauX, Systèmes dynamiques dissipatifs et applications, RMA, 17, Masson, 1991.

[22] A. Haraux, M. Jendoubi, Convergence of solutions of second-order gradient-like systems with analytic nonlinearities, J. Differential Equations, 144, 2 (1998), 313-320.

[23] C. Lageman, Pointwise convergence of gradient-like systems, Math. Nachr., 280, (13-14), (2007), 1543-1558.

[24] S. Lefschetz, Differential Equations: Geometric Theory, second edition, Pure and Applied Mathematics, Vol. VI, Interscience Publishers, New York London, 1963.

[25] P. E. MAINGÉ, Fixed-point iterations coupled with relaxation factors and inertial effects, Nonlinear Analysis: Theory, Methods, Applications, 72, 2 (2010), 720-733.

[26] P. E. Maingé, N. Merabet, A new inertial-type hybrid projection- proximal algorithm for monotone inclusions, Applied Mathematics and Computation, (2009), doi:10.1016/j.amc.2009.10.26.

[27] P. E. Maingé, A. Moudafi, Convergence of new inertial proximal methods for DC programming, SIAM J. Optimization, 19, 1 (2008), 397-413.

[28] P. E. Maingé, A. Moudafi, A proximal method for maximal monotone operators via discretization of a first order dissipative dynamical system, J. Convex Analysis, 14, 4 (2007), 869-878.

[29] J. J. Moreau, Standard inelastic shocks and the dynamics of unilateral constraints: in Unilateral problems in structural analysis, CISM Courses, Vol 288, Springer Verlag, 1985, 173-221.

[30] L. PaOli, M. Schatzman, Mouvement à un nombre fini de degrés de liberté avec contraintes unilatérales: cas avec perte d'énergie, Mod. Math. Anal. Num., 27 (1993), 673-717.

[31] L. Paoli, M. Schatzman, Penalty approximation for nonsmooth constraints in vibro-impact, J. Differential Equations, 177 (2001), 375-418.

[32] L. PAOLI, M. SCHATZMAN, A numerical scheme for impact problems I and II, SIAM J. Numer. Anal., 40, (2) (2002), 702-733, 734-768.

[33] L. PaOli, M. Schatzman, Penalty approximation for dynamical systems submitted to multiple nonsmooth constraints, Multibody System Dynamics, 8 (2003), 347-366.

[34] A. Petrov, M. SchatZman, One-dimensional viscoelastodynamics with Signorini boundary conditions, CRAS Paris 334, 11 (2002), 983-988. 
[35] M. Schatzman, A class of nonlinear differential equations of second order in time, Nonlinear Anal., 2 (1978), 355-373. 